\title{
La investigación en la USMA, un estudio de su evolución reciente.
}

\section{Luis Wong Vega ${ }^{1, *}$, Rubén Díaz ${ }^{1}$, Carmen Solano ${ }^{1}$ y Melva Palacios de Mon ${ }^{2}$}

${ }_{1}$ Dirección de Investigación y Desarrollo, Universidad Católica Santa María La Antigua (USMA), Panamá, República de Panamá.

2 Vicerrectoría de Investigación, Postgrado y Extensión, Universidad Católica Santa María La Antigua (USMA), Panamá, República de Panamá.

*Autor para correspondencia. Correo electrónico: lwong@usma.ac.pa

Recibido: 25 de enero de 2017 Aceptado: 08 de febrero de 2017

\begin{abstract}
.
Since July 2015 to date, several R \& D management indicators at USMA have registered significant increases, showing significant improvement in indexes that measure scientific productivity in this university, among others. In order to know the causes of this phenomenon and to determine measures that guarantee their sustainability and permanent impulse, a transversal research scheme was designed. Initially, a survey was applied to a representative segment of directly involved staff members (full-time professors and researchers). The survey procedure was determined according to Kerlinger and Lee (2002), using mostly Likert type scales. In-depth interviews were conducted with key, internal stakeholders (key senior management personnel). These interviews were developed modifying the procedure described by Taylor and Bogdan (1992). This information was used as input to prepare a comprehensive examination according to the method of comparative results analysis, according to Mayring (2014), which corroborated the results of both techniques. As a result, the causes of qualitative and quantitative increases have been preliminarily characterized in almost all management indicators. Based on the findings obtained, practically all the pertinent regulations for research and development have been reformulated, current programs have been redesigned and new complementary schemes have been created, which entered into a full application phase at the beginning of 2017.

Keywords. Research; University; Research management; Qualitative research; University processes; Accreditation.

\section{Resumen.}

Desde julio de 2015 hasta la fecha, diversos indicadores de la gestión de la I+D en la USMA han registrado incrementos importantes, recuperándose una mejora significativa en los índices que miden productividad científica en esta universidad, entre otros. Para conocer las causas de este fenómeno y determinar medidas que garanticen su sostenibilidad e impulso permanente, se diseñó un esquema de investigación transversal. Inicialmente, se aplicó una encuesta a un segmento representativo de los estamentos directamente involucrados (profesores e investigadores, ambos de dedicación exclusiva),
\end{abstract}


Invest. pens. crit. (ISSN 1812-3864)

Vol. 5, No. 1, enero-abril 2017

pp. $28-40$

determinado según Kerlinger y Lee (2002), empleando mayormente escalas tipo Likert. El margen de error admitido en el sondeo fue de 3\%. Se efectuaron entrevistas a profundidad con actores claves, internos (personal clave de alta gerencia), según el procedimiento de Taylor y Bogdan (1992), modificado. Esta información fue utilizada como insumo para preparar un análisis integral según el método de análisis comparativo de resultados, según Mayring (2014), el cual corroboró los resultados de ambas técnicas. Como resultado, se han caracterizado preliminarmente las causas de los incrementos, cualitativos y cuantitativos, en casi todos los indicadores de gestión. Con base en los hallazgos obtenidos, se ha reformulado prácticamente toda la normatividad pertinente a investigación y desarrollo, se han rediseñado programas vigentes y se han creado esquemas complementarios nuevos, los cuales entraron en fase de plena aplicación al inicio del año 2017.

Palabras clave. Investigación; Universidad; Gestión de la investigación; Investigación cualitativa; Procesos universitarios; Acreditación.

\section{Introducción.}

Como menciona el académico colombiano Dr. Jorge Hernán Sierra: "En esta nueva etapa de la humanidad, que Alvin Toffler ha denominado tercera ola de desarrollo, y cuya base se centra en el conocimiento, las universidades son las más llamadas a generar investigación, por cuanto se supone que allí están las personas más idóneas y experimentadas en su ciencia o disciplina específica para compartir el acervo de saberes, guiar en la búsqueda a quienes apenas comienzan la formación en la educación superior y servir como apoyo al desarrollo de la sociedad" [1].

Nadie duda de la importancia de la investigación como proceso fundamental dentro de la vida de la institución universitaria moderna. Empero, el tratamiento al tema del desarrollo investigativo universitario no es parejo a nivel regional ni a nivel nacional, a escala de un mismo país. Las diferencias se hacen palpar en forma notoria cuando comparamos los resultados de la investigación entre universidades públicas y particulares [2:4].

Históricamente (y salvo honrosas excepciones) la investigación en universidades privadas de América Latina ha sido un factor secundario para muchas entidades, que han privilegiado la función formativa por encima de las otras, especialmente la de investigación [3:5].

Los procesos de acreditación impulsados por el Consejo Nacional de Evaluación y Acreditación Universitaria de Panamá (CONEAUPA) han puesto una fuerte presión para que todas las universidades, incluyendo a la Universidad Católica Santa María la Antigua (USMA), cumplan metas específicas dentro de sus planes de gestión y/o sus planes de mejora, dirigidas a potenciar sus actividades de investigación.

En este documento, el factor "Investigación e Innovación” es el segundo de los cuatro ámbitos mayores sujetos a un examen y a una ponderación rigurosa y permanente por parte de CONEAUPA [6]. 
Invest. pens. crit. (ISSN 1812-3864)

Vol. 5, No. 1, enero-abril 2017

pp. $28-40$

Por otra parte, la misma Constitución Apostólica para las Universidades Católicas "Ex Corde Ecclesia" establece claramente que la misión fundamental de toda Universidad Católica es "la constante búsqueda de la verdad mediante la investigación, la conservación y la comunicación del saber para el bien de la sociedad" [7].

Para la USMA, la investigación es parte esencial de su mandato fundacional [8]. No obstante este mandato, el apoyo a la investigación en la USMA ha sido irregular, pasando de etapas de relativo auge a fases en donde su expresión ha sido bastante limitada y modesta.

Con la llegada de la nueva administración y en cuanto a resultados de la gestión de la investigación en la universidad, se han emprendido pasos significativos que marcan una diferencia cualitativa y cuantitativa evidente, habiendo hecho avances significativos en una serie de aspectos críticos [9].

Como se ha señalado [10], los datos cuantitativos demuestran que desde la entrada de la administración actual hasta hoy, la USMA ha avanzado significativamente en casi todos los parámetros de medición. Por ejemplo, comparando la situación entre el año 2014 y el año 2016 (Tabla 1).

Tabla 1.

Cuadro comparativo en resultados globales de gestión

\begin{tabular}{|c|c|c|}
\hline Parámetro & 2014 & 2016 \\
\hline $\begin{array}{l}\text { 1. Proyectos de } \mathrm{I}+\mathrm{D} \text { presentados a Convocatoria } \\
\text { interna para subvenciones }\end{array}$ & 1 & 21 \\
\hline 2. Proyectos de $\mathrm{I}+\mathrm{D}$ aprobados & 0 & 15 \\
\hline $\begin{array}{l}\text { 3. Proyectos de I+D presentados a SENACYT a } \\
\text { convocatoria para subsidios }\end{array}$ & 5 & 10 \\
\hline 4. Proyectos de I+D aprobados por SENACYT & 0 & 4 \\
\hline $\begin{array}{l}\text { 5. Cursos de Capacitación en temas de } \\
\text { investigación }\end{array}$ & $\begin{array}{l}2 \text { cursos } \\
26 \text { personas }\end{array}$ & $\begin{array}{l}4 \quad \text { cursos }(\mathrm{de} \\
\text { noviembre 2015 a } \\
\text { octubre 2016) } \\
61 \text { personas }\end{array}$ \\
\hline
\end{tabular}

6. Participaciones de la USMA en Congreso 11 (2 ponencias 16 (8 ponencias Nacional de Ciencia y Tecnología de APANAC orales) orales) (mesas redondas, exposiciones orales, carteles) 
Invest. pens. crit. (ISSN 1812-3864)

Vol. 5, No. 1, enero-abril 2017

pp. $28-40$

7. Indexación de la revista institucional de 0 investigación IPC (en LatIndex)

8. Porcentaje de artículos derivados de proyectos de investigación
20 artículos, 7 de investigación $(35 \%)$
1

13 artículos, 7 de investigación $(53.84 \%)$

El presente estudio busca analizar, documentar y extraer conclusiones derivadas de la nueva situación, de cara a hacerla permanente y a darle un impulso aún mayor. Igualmente, producir insumos para el proceso de análisis y redefinición de políticas universitarias, con base a hechos y dato corroborados en forma científica.

\section{$2 \quad$ Materiales y métodos.}

\subsection{Características generales de este estudio.}

El presente estudio es una investigación de campo, de corte transversal y de tipo exploratorio, descriptivo y explicativo. Se apoya en técnicas de análisis cualitativo y emplea tres herramientas: encuestas, el análisis comparativo de información y entrevistas a profundidad. En los casos de las dos primeras técnicas, la información fue ordenada y tabulada y sujeta a análisis posteriores según el procedimiento para el análisis cualitativo de datos por comparación.

\section{$2.2 \quad$ Encuestas.}

Se desarrolló una encuesta con base a los parámetros generales delineados por Kerlinger y Lee [11]. Esta encuesta administrada en línea era anónima e iba dirigida a evaluar la percepción de profesores e investigadores con relación al estado actual de la investigación en la USMA, compuesta de la siguiente forma: una pregunta de matriz de opción múltiple para valorar (a) Conocimiento, (b) Participación y (c) Satisfacción con cuatro programas de la Dirección de Investigación; una pregunta de matriz de opción múltiple para valorar la calificación a cinco factores relacionados con la investigación; una pregunta dicotómica para identificar la percepción de cambios en lo que se refiere a investigación; dos preguntas abiertas: una para describir los cambios percibidos y otra para indagar acerca de los factores que explican el cambio. La muestra de 21 personas (de un total de 28), estaba compuesta por investigadores a tiempo completo, investigadores asociados, profesores a tiempo completo, profesores con proyectos de investigación y estudiantes tesistas.

\section{$2.3 \quad$ Entrevistas.}

El procedimiento se basó en la guía desarrollada por Taylor and Bogdan [12]. La guía estándar de entrevista fue diseñada para aplicación individual. La misma era monotemática, estructurada, con doce preguntas cerradas y con un orden fijo de preguntas. Las entrevistas se aplicaron a cinco cuadros de 
Invest. pens. crit. (ISSN 1812-3864)

Vol. 5, No. 1, enero-abril 2017

pp. $28-40$

alta gerencia de la universidad (rector, tres vicerrectores y secretaria general) y a sus decanos (seis cabezas de facultad).

\subsection{Análisis comparativo de información.}

El procedimiento de análisis comparativo de datos, se desarrolló adaptando el método desarrollado por Mayring [13]. Empleando estos procedimientos para el análisis profundo de contenidos, los datos de ambas técnicas previas son primero resumidos (summarized) en sus aspectos conceptuales más básicos estableciéndose categorías (cathegorized). La información categorizada es posteriormente procesada por medio de cuadros analítico-comparativos, en donde se le somete a criterios de análisis de paráfrasis, de generalización y de reducción, corte, combinación, construcción e integración.

\section{Resultados.}

La encuesta ya descrita fue aplicada en línea, durante un lapso de tres semanas y tuvo aproximadamente un $40 \%$ de participación. Los resultados, por ítem, se presentan en la Tabla 2.

Tabla 2.

Respuestas a cuestionario de encuesta.

\begin{tabular}{|c|c|c|}
\hline & Pregunta & Respuestas \\
\hline 1 & ¿Cuál es su Vinculación a la USMA? & $\begin{array}{l}\text { Investigador TC: } 5 / 21,24 \% \\
\text { Investigador Asociado: } 5 / 21,24 \% \\
\text { Investigador TP: } 5 / 21,24 \% \\
\text { Profesor TC: } 4 / 21,19 \% \\
\text { Estudiante: } 2 / 21,10 \%\end{array}$ \\
\hline 2 & $\begin{array}{l}\text { ¿Está conduciendo algún proyecto de } \mathrm{I}+\mathrm{D} \text { registrado en } \\
\text { la Dirección de Investigación actualmente? }\end{array}$ & $\begin{array}{l}\text { Si: } 13 / 21,62 \% \\
\text { No: } 8 / 21,38 \%\end{array}$ \\
\hline 3 & $\begin{array}{l}\text { ¿Conoce el programa de estímulos a la } \mathrm{I}+\mathrm{D} \\
\text { (subvenciones a proyectos)? }\end{array}$ & $\begin{array}{l}\text { Si: } 20 / 21,95 \% \\
\text { No: } 1 / 21,5 \%\end{array}$ \\
\hline 4 & ¿Ha participado en el programa de estímulos a la I+D? & $\begin{array}{l}\text { Si: } 13 / 21,62 \% \\
\text { No: } 8 / 21,38 \%\end{array}$ \\
\hline 5 & $\begin{array}{l}\text { ¿Qué tan satisfecho está con el programa de estímulos a } \\
\text { la I+D? }\end{array}$ & $\begin{array}{l}\text { Muy satisfecho: } 9 / 21 \\
\text { Satisfecho: } 8 / 21 \\
\text { Regular: } 3 / 21 \\
\text { Insatisfecho: } 0 / 21 \\
\text { Muy insatisfecho: } 1 / 21\end{array}$ \\
\hline 6 & $\begin{array}{l}\text { ¿Conoce la revista Investigación y Pensamiento Crítico } \\
\text { (IPC)? }\end{array}$ & $\begin{array}{l}\text { Si: } 21 / 21 \\
\text { No: } 0 / 21\end{array}$ \\
\hline
\end{tabular}


Invest. pens. crit. (ISSN 1812-3864)

Vol. 5, No. 1, enero-abril 2017

pp. $28-40$

\begin{tabular}{ll}
\hline Pregunta & Respuestas \\
\hline
\end{tabular}

$7 \quad$ ¿Ha publicado en esta revista?

Si: $9 / 21,43 \%$

No: $12 / 21,57 \%$

8 ¿Qué tan satisfecho está con la calidad de la revista IPC?

Muy satisfecho: $10 / 21$

Satisfecho: 8/21

Regular: 2/21

Insatisfecho: $1 / 21$

Muy insatisfecho: 0/21

9 ¿Conoce del Programa de Capacitación en Aspectos

Técnicos de la Investigación?

Si: $41 / 21,67 \%$

No: $7 / 21,33 \%$

10 ¿Ha participado en este Programa de Capacitación Si: 8/21, 38\% especializada? No: $13 / 21,62 \%$

11 ¿Qué tan satisfecho está con este Programa de Muy satisfecho: 8/21 Capacitación?

Satisfecho: $8 / 21$

Regular: 3/21

Insatisfecho: $1 / 21$

Muy insatisfecho: 1/21

12 ¿Conoce del Programa de Apoyo a la participación e Convocatorias Externas (i.e. SENACYT)?

Si: $71 / 21,81 \%$

No: 4/21, $19 \%$

13 ¿Ha participado en este Programa?

Si: $11 / 21,52 \%$

No: $10 / 21,48 \%$

14 ¿Qué tan satisfecho está con este Programa de Apoyo a la participación e Convocatorias Externas?

Muy satisfecho: 6/21

Satisfecho: 4/21

Regular: 9/21

Insatisfecho: $1 / 21$

Muy insatisfecho: $1 / 21$

15 Recursos humanos dedicados a la Investigación

Muy satisfecho: 6/21

Satisfecho: 6/21

Regular: 4/21

Insatisfecho: $3 / 21$

Muy insatisfecho: 2/21

16 Cantidad de proyectos que componen la cartera de investigación de la universidad actualmente

Muy satisfecho: 4/21

Satisfecho: $10 / 21$

Regular: 4/21

Insatisfecho: $2 / 21$

Muy insatisfecho: 1/21 
Invest. pens. crit. (ISSN 1812-3864)

Vol. 5, No. 1, enero-abril 2017

pp. $28-40$

\section{Pregunta \\ Respuestas}

17 Opinión sobre políticas y normativas vigentes para la Muy satisfecho: 9/21 Investigación

Satisfecho: $5 / 21$

Regular: 3/21

Insatisfecho: $3 / 21$

Muy insatisfecho: $1 / 21$

18 Opinión sobre el sistema de gestión de la investigación actual

Muy satisfecho: $9 / 21$

Satisfecho: $5 / 21$

Regular: 4/21

Insatisfecho: $2 / 21$

Muy insatisfecho: $1 / 21$

19 ¿Percibe Usted un cambio en el estado actual de la Si: $19 / 21,90 \%$ investigación en la USMA comparado a dos años atrás? No. 2/21, 10\%

Las entrevistas fueron aplicadas a cuadros de la alta gerencia (4 de 5 respondientes, $80 \%$ de respuesta) y a decanos (4 de 6 respondientes, $66 \%$ de respuesta). Los resultados de estas entrevistas se presentan a continuación, en tres tablas:

Tabla 3.

Cuadro resumen de respuestas a preguntas centrales de las entrevistas

\begin{tabular}{|c|c|c|c|c|c|}
\hline Posición & $\begin{array}{l}\text { Valoración sobre } \\
\text { la USMA como } \\
\text { ente generador de } \\
\text { investigación y } \\
\text { productividad } \\
\text { intelectual }\end{array}$ & $\begin{array}{l}\text { Utilidad } r \\
\text { relevancia de sus } \\
\text { aportes a las } \\
\text { necesidades de la } \\
\text { sociedad } \\
\text { panameña }\end{array}$ & $\begin{array}{l}\text { Comparando lo } \\
\text { observado hace } \\
\text { tres años a la } \\
\text { fecha, ¿hay un } \\
\text { cambio? Defina } \\
\text { este cambio, si lo } \\
\text { hay }\end{array}$ & $\begin{array}{l}\text { Razones } \\
\text { responsables de } \\
\text { ese cambio o falta } \\
\text { de cambio }\end{array}$ & $\begin{array}{l}\text { Qué hay que hacer } \\
\text { o mejorar para } \\
\text { consolidar a la } \\
\begin{array}{l}\text { Investigación } \\
\text { dentro de la } \\
\text { cultura } \\
\text { institucional }\end{array} \\
\end{array}$ \\
\hline Rector & $\begin{array}{l}\text { Mucho potencial. } \\
\text { Prestigio. Misión: } \\
\text { formar líderes. } \\
\text { Univ. Sin fines de } \\
\text { lucro }\end{array}$ & $\begin{array}{l}\text { Sí, pero debe } \\
\text { incrementar } \\
\text { pertinencia hacia } \\
\text { problemas sociales }\end{array}$ & $\begin{array}{l}\text { Sí ha habido un } \\
\text { cambio total. } \\
\text { Aumento de } \\
\text { inversión, } \\
\text { actividades, } \\
\text { correspondencia } \\
\text { con objetivos de la } \\
\text { universidad. } \\
\text { Cambio positivo y } \\
\text { significativo. }\end{array}$ & $\begin{array}{lrr}\text { Una } & \text { Actitud } \\
\text { diferente, dirigida al } \\
\text { rescate de } & \text { los } \\
\text { valores de } & \text { la } \\
\text { universidad. } & \end{array}$ & $\begin{array}{l}\text { Promover la I+D a } \\
\text { todos los niveles. } \\
\text { Potenciar la actitud } \\
\text { investigativa, } \\
\text { especialmente en el } \\
\text { tema de las tesis. } \\
\text { Inversión en } \\
\text { recursos humanos y } \\
\text { materiales. }\end{array}$ \\
\hline Vicerrector 1 & $\begin{array}{l}\text { Universidad } \\
\text { Formación } \\
\text { consistente } \\
\text { integral. }\end{array}$ & $\begin{array}{l}\text { Si, a pesar de que ha } \\
\text { habido cierta } \\
\text { irregularidad, ha } \\
\text { habido ejemplos } \\
\text { esporádicos en los } \\
\text { últimos años de } \\
\text { casos muy } \\
\text { relevantes. }\end{array}$ & $\begin{array}{l}\text { Sí, ha habido } \\
\text { cambio y ha sido } \\
\text { positivo } \\
\text { significativo, desde } \\
\text { la parte teórica a la } \\
\text { práctica. }\end{array}$ & $\begin{array}{l}\text { Primero, la visión de } \\
\text { las altas autoridades } \\
\text { actuales. Segundo, el } \\
\text { empeño } \\
\text { personal a cargo del } \\
\text { área. En donde este } \\
\text { cambio no se } \\
\text { manifiesta muy } \\
\text { fuerte puede } \\
\text { deberse a un tema } \\
\text { de } \\
\text { coyuntural. }\end{array}$ & $\begin{array}{l}\text { Mantener la misma } \\
\text { visión. Apuntalar } \\
\text { áreas, evaluar, } \\
\text { detectar problemas } \\
\text { y resolverlos. }\end{array}$ \\
\hline
\end{tabular}


Invest. pens. crit. (ISSN 1812-3864)

Vol. 5, No. 1, enero-abril 2017

pp. $28-40$

\begin{tabular}{|c|c|c|c|c|c|}
\hline Vicerrector 2 & $\begin{array}{l}\text { La USMA es una } \\
\text { institución con } \\
\text { trayectoria en el } \\
\text { medio universitario } \\
\text { local. En los } \\
\text { últimos años perdió } \\
\text { oportunidades de } \\
\text { innovar y de } \\
\text { potenciar su esencia } \\
\text { académica. Pero es } \\
\text { una comunidad } \\
\text { académica real y sus } \\
\text { miembros tienen un } \\
\text { alto sentido de } \\
\text { pertenencia. }\end{array}$ & $\begin{array}{lr}\text { Sí, pero aún } & \text { debe } \\
\text { definir un } & \text { nicho } \\
\text { especial } & \text { en } \\
\text { investigación } & \text { y } \\
\text { especializarse } & \text { y } \\
\text { desarrollarlo, para } \\
\text { hacer más efectivos } \\
\text { sus aportes. }\end{array}$ & $\begin{array}{l}\text { Sí. En los últimos } 18 \\
\text { meses ha habido un } \\
\text { salto cualitativo } \\
\text { importante. }\end{array}$ & $\begin{array}{l}\text { Cambio en la } \\
\text { mentalidad de la alta } \\
\text { gerencia respecto a } \\
\text { lo que es realmente } \\
\text { importante para una } \\
\text { universidad } \\
\text { moderna. Cambio } \\
\text { de mentalidad en la } \\
\text { comunidad respecto } \\
\text { a involucrarse en } \\
\text { estas tareas de } \\
\text { investigación. }\end{array}$ & 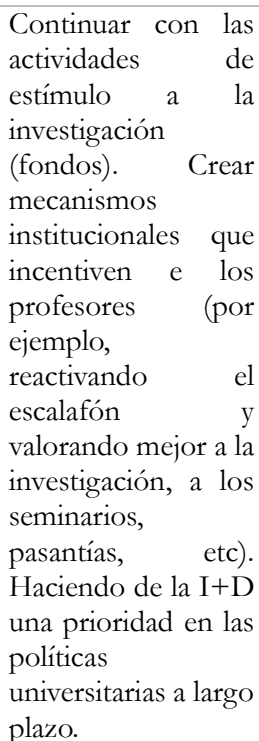 \\
\hline Vicerrector 3 & $\mathrm{~N} / \mathrm{A}$ & $\mathrm{N} / \mathrm{A}$ & $\mathrm{N} / \mathrm{A}$ & $\mathrm{N} / \mathrm{A}$ & $\mathrm{N} / \mathrm{A}$ \\
\hline $\begin{array}{l}\text { Secretaria } \\
\text { General }\end{array}$ & $\begin{array}{l}\text { Dentro del entorno } \\
\text { es de primer nivel. } \\
\text { Una universidad } \\
\text { seria, dedicada a la } \\
\text { formación integral. } \\
\text { Con una } \\
\text { administración que } \\
\text { por primera vez se } \\
\text { interesa realmente } \\
\text { en la investigación. }\end{array}$ & $\begin{array}{l}\text { Sí, la USMA posee } \\
\text { programas } \\
\text { formativos } \\
\text { pertinentes, con un } \\
\text { fuerte componente } \\
\text { ético. }\end{array}$ & $\begin{array}{l}\text { Sí, positivo y muy } \\
\text { significativo. }\end{array}$ & $\begin{array}{l}\text { Mayor atención de } \\
\text { las autoridades. } \\
\text { Mayor inversión en } \\
\text { I+D. }\end{array}$ & $\begin{array}{l}\text { Dar a conocer a la } \\
\text { comunidad el valor } \\
\text { de la investigación } \\
\text { en manos de todos. } \\
\text { Reforzar } \\
\text { económicamente a } \\
\text { la Dirección de } \\
\text { Investigación. }\end{array}$ \\
\hline Decano 1 & $\begin{array}{lr}\text { Nuestra } & \\
\text { comparación } & \text { debe } \\
\text { ser con los } & \text { mejores } \\
\text { del } & \text { mundo. } \\
\text { Fortaleza } & \text { en } \\
\text { formación } & \text { de } \\
\text { líderes. } & \end{array}$ & $\begin{array}{l}\text { Sí, generaciones de } \\
\text { nuestros egresados } \\
\text { han sido los } \\
\text { transformadores de } \\
\text { este país. La USMA } \\
\text { ha sido propulsor } \\
\text { permanente de una } \\
\text { forma más } \\
\text { innovadora de } \\
\text { pensar. }\end{array}$ & $\begin{array}{l}\text { Si, total. En los } \\
\text { últimos años se ha } \\
\text { desmitificado la } \\
\text { investigación y se le } \\
\text { ha transformado en } \\
\text { algo interesante y } \\
\text { factible para los } \\
\text { profesores. }\end{array}$ & $\begin{array}{lr}\text { La voluntad de los } \\
\text { directivos de la } \\
\text { universidad. } \\
\text { equipo que ha } \\
\text { estado detrás de este } \\
\text { impulso, desde la } \\
\text { gestión anterior a la } \\
\text { actual. }\end{array}$ & $\begin{array}{lr}\text { Mayor inversión } & \text { de } \\
\text { recursos } & \text { y } \\
\text { dedicación a } & \text { la } \\
\text { formación } & \text { en } \\
\text { investigación. } & \end{array}$ \\
\hline Decano 2 & $\begin{array}{l}\text { La USMA tiene un } \\
\text { modelo educativo } \\
\text { sólido. No obstante, } \\
\text { en el terreno } \\
\text { investigativo nos } \\
\text { falta. Ahora se está } \\
\text { haciendo algo, con } \\
\text { directrices } \\
\text { concretas } \\
\text { motivación. }\end{array}$ & $\begin{array}{l}\text { En algunos aspectos } \\
\text { sí. Los estándares } \\
\text { nacionales son bajos } \\
\text { y tenemos potencial } \\
\text { para mucho más. }\end{array}$ & $\begin{array}{l}\text { Sí, mucho. Este } \\
\text { cambio es positivo y } \\
\text { significativo. }\end{array}$ & $\begin{array}{lr}\text { El cambo en la } \\
\text { administración } \\
\text { universitaria, que } \\
\text { ahora } & \text { está } \\
\text { interesada en } & \text { la } \\
\text { búsqueda de } & \text { la } \\
\text { calidad y } & \text { da } \\
\text { prioridad a } & \text { la } \\
\text { investigación. } \\
\text { Tenemos ahora } \\
\text { estructuras } \\
\text { investigación de } \\
\text { funcionan. }\end{array}$ & $\begin{array}{l}\text { Exigir un aumento } \\
\text { en el porcentaje de } \\
\text { investigadores } \\
\text { dentro del cuerpo } \\
\text { docente. Fomentar } \\
\text { la investigación } \\
\text { como alternativa } \\
\text { para estudiantes. } \\
\text { Generar incentivos } \\
\text { para los que } \\
\text { participen (créditos, } \\
\text { estímulos } \\
\text { económicos, } \\
\text { laborales, etc). }\end{array}$ \\
\hline Decano 3 & $\begin{array}{l}\text { La USMA es una } \\
\text { universidad bien } \\
\text { ubicada, con una }\end{array}$ & $\begin{array}{l}\text { Sí. Debe incentivar } \\
\text { más al sector, con } \\
\text { buenos }\end{array}$ & $\begin{array}{ll}\text { Sí, cambios } & \text { muy } \\
\text { grandes. } & \text { Este }\end{array}$ & $\begin{array}{lr}\text { La disposición } \\
\text { administrativa. } & \text { El } \\
\text { énfasis } & \text { de }\end{array}$ & $\begin{array}{lrr}\text { Debe reforzar el } & \text { el } \\
\text { aspecto de } & \text { sus } \\
\text { docentes. } & & \mathrm{La}\end{array}$ \\
\hline
\end{tabular}


Invest. pens. crit. (ISSN 1812-3864)

Vol. 5, No. 1, enero-abril 2017

pp. $28-40$

\begin{tabular}{|c|c|c|c|c|c|}
\hline & $\begin{array}{l}\text { organización y un } \\
\text { entorno académico } \\
\text { fuertes. }\end{array}$ & $\begin{array}{l}\text { profesionales y más } \\
\text { contactos. }\end{array}$ & $\begin{array}{l}\text { cambio ha sido muy } \\
\text { positivo. }\end{array}$ & $\begin{array}{lr}\text { CONEAUPA } & \text { ha } \\
\text { hecho mucho } & \text { por } \\
\text { reforzar } & \text { este } \\
\text { ámbito. } & \end{array}$ & $\begin{array}{l}\text { investigación debe } \\
\text { llevarse al aula. }\end{array}$ \\
\hline Decano 4 & $\begin{array}{l}\text { Entre los primeros } \\
\text { lugares a nivel local, } \\
\text { por la calidad de sus } \\
\text { docentes } \\
\text { investigadores y por } \\
\text { el gran esfuerzo de } \\
\text { la administración al } \\
\text { otorgar recursos } \\
\text { para el área. }\end{array}$ & $\begin{array}{l}\text { Muy pertinente, por } \\
\text { vía de la extensión y } \\
\text { la proyección } \\
\text { universitaria, } \\
\text { empleando } \\
\text { mecanismos como } \\
\text { el servicio social, la } \\
\text { ayuda comunitaria, } \\
\text { etc. }\end{array}$ & $\begin{array}{l}\text { Sí, altamente } \\
\text { positivo, inédito } \\
\text { hasta el día de hoy } \\
\text { dentro de la } \\
\text { universidad. }\end{array}$ & $\begin{array}{l}\text { La disposición de las } \\
\text { autoridades } \\
\text { superiores, } \\
\text { comenzando con el } \\
\text { interés del Rector. } \\
\text { También por la } \\
\text { adjudicación de un } \\
\text { presupuesto real } \\
\text { para esto. } \\
\text { Finalmente, el } \\
\text { nuevo sentido de } \\
\text { identidad que se } \\
\text { percibe en los } \\
\text { profesores. }\end{array}$ & $\begin{array}{l}\text { Deben conducirse } \\
\text { acciones para } \\
\text { reforzar } \\
\text { capacitación de los } \\
\text { profesores. A nivel } \\
\text { de las facultades, } \\
\text { debe promoverse } \\
\text { más la participación } \\
\text { de docentes. Debe } \\
\text { darse más } \\
\text { divulgación a los } \\
\text { beneficios para } \\
\text { aquellos que se } \\
\text { involucren en la } \\
\text { investigación. }\end{array}$ \\
\hline
\end{tabular}

Tabla 4.

Cuadro resumen de respuestas a preguntas centrales de las entrevistas, por respondiente.

\section{Posición Observaciones finales} Rector universidad. Fomentar alianzas con entes que puedan
sentido, como con SENACYT y vínculos internacionales.

Debe aumentarse el compromiso con el fomento de la investigación en la

Vicerrector 1

La orientación actual de la investigación es positiva y por vía de la evaluación regular, habrá que apuntalar en donde haya áreas con algún rezago.

Lo obtenido en los últimos 18 meses hay que hacerlo extensivo a las sedes

Vicerrector 2 regionales, principalmente aquellas que tiene algún rasgo particular (como la sede de Azuero, que posee careras propias en el ámbito agrario-ambiental).

Vicerrector $3 \quad \mathrm{~N} / \mathrm{A}$

Secretaria Debe fomentarse la investigación universitaria, la investigación sobre los General procesos administrativos y docentes dentro de la universidad.

Decano $1 \quad$ Sin comentarios.

Decano 2

Vamos por buen camino pero no debemos dormirnos ni distraernos ni perder el tiempo con aquellos a quienes esta labor no les interesa. 
Invest. pens. crit. (ISSN 1812-3864)

Vol. 5, No. 1, enero-abril 2017

pp. $28-40$

\begin{tabular}{ll}
\hline Posición & Observaciones finales \\
\hline Decano 3 & $\begin{array}{l}\text { Debe intervenirse en los cursos de metodología de la Investigación, con } \\
\text { profesores con experiencia investigativa que pueda ser traspasada a los } \\
\text { estudiantes. }\end{array}$ \\
Decano 4 & $\begin{array}{l}\text { Es muy importante que la USMA refuerce sus actividades de investigación, } \\
\text { pilar fundamental de la acreditación. Para ello deben buscarse más recursos y } \\
\text { mantenerse e incrementarse el apoyo al sector. }\end{array}$ \\
\hline
\end{tabular}

Los resultados de ambos procedimientos fueron sometidos al proceso de análisis, contrastación, categorización y sumarización, según Mayring (op. cit.), identificándose diez aspectos centrales de coincidencia, no siendo detectados antagonismo ni exclusión. Los resultados del análisis se muestran a continuación:

Tabla No. 5 Resultados del análisis contrastativo

Tabla 5.

Resultados del análisis contrastativo

\begin{tabular}{lll}
\hline Etapa & Categoría identificada & Frecuencia \\
\hline 1 & $\begin{array}{l}\text { Recursos (asignación de dinero para programas, Fondo de } \\
\text { Investigación) }\end{array}$ & Muy Alta \\
2 & Necesidad de Seguimiento (apoyo técnico, clínicas, etc.) & Muy Alta \\
3 & Escalafón (carrera académica que valore investigación) & Muy Alta \\
4 & Continuidad (en políticas internas de apoyo) & Alta \\
5 & Claridad (líneas y orientaciones definidas) & Alta \\
6 & Formación (acciones de capacitación al personal) & Media alta \\
7 & Acreditación (reconocimiento externo, cultura de calidad, & Media alta \\
8 & evaluación) & \\
9 & Sostenibilidad financiera & Media \\
10 & Imagen Institucional & Media \\
\hline
\end{tabular}


Invest. pens. crit. (ISSN 1812-3864)

Vol. 5, No. 1, enero-abril 2017

pp. $28-40$

\section{$4 \quad$ Discusión}

Los resultados de los tres procedimientos aplicados arrojaron resultados sumamente consistentes entre sí. Reflejan resultados similares y complementarios.

Respecto a la encuesta, en prácticamente todos los criterios de valoración y de conocimiento, el índice de satisfacción (satisfecho y muy satisfecho) supera el 50\%, excepto el ítem 14 (participación en convocatorias externas).

Analizando estos resultados, vemos que la media estadística de los criterios referidos al apoyo directo a proyectos $(3.86,4.10,3.86,3.67)$, alcanza un valor de 3.8725 , equivalente a un $77.45 \%$ de satisfacción. Aquella referida a actividades conexas $(2.57,2.52,2.62,2.90)$ promedia 2.65 , equivalente a un $53 \%$ de satisfacción. La media de aprobación global alcanza 3.26 o sea $65.2 \%$.

En algunos índices de participación (ítems 6, 10 y 13, por ejemplo) se nota que aún hay aspectos en donde la participación es baja y hay que efectuar acciones específicas de motivación y reclutamiento, quizás por vía de acciones de seguimiento y atención personalizada al investigador.

La Encuesta demuestra que la gran mayoría de los cuadros académicos de la Universidad, conoce los programas de la Dirección de Investigación y que está bastante satisfecha con sus resultados. Igualmente, reconoce que hay un cambio en este orden dentro de la USMA.

En cuanto a los resultados de las entrevistas, los mismos pueden resumirse en el siguiente gráfico:

Tabla No. 6 Conclusiones globales de cada tema tratado en la entrevista

\begin{tabular}{|c|c|}
\hline Preguntas & Resumen (síntesis de respuestas) \\
\hline $\begin{array}{lr}\text { Valoración sobre la } \\
\text { USMA como ente } \\
\text { generador } \\
\text { investigación de } \\
\text { productividad } \\
\text { intelectual }\end{array}$ & $\begin{array}{l}\text { Se le percibe como una institución de primer nivel dentro del entorno local. Posee fortalezas y } \\
\text { rasgos propios, entre los que destaca la formación integral, su aporte formando líderes y su } \\
\text { carácter de universidad sin fines de lucro. En el terreno investigativo ha dejado pasar } \\
\text { oportunidades pero esa situación ha cambiado y se está mejorando mucho en este terreno. }\end{array}$ \\
\hline $\begin{array}{l}\text { Utilidad y relevancia } \\
\text { de sus aportes a las } \\
\text { necesidades de la } \\
\text { sociedad panameña }\end{array}$ & $\begin{array}{l}\text { Sí, considerando que los estándares locales son bajos. No obstante ha habido ejemplos de aportes } \\
\text { importantes a la sociedad panameña, derivados de nuestra labor, especialmente en el aspecto } \\
\text { formativo, propulsor de una forma innovadora de pensar y actuar. }\end{array}$ \\
\hline $\begin{array}{l}\text { Comparando lo } \\
\text { observado hace tres } \\
\text { años a la fecha, chay } \\
\text { un cambio? Defina } \\
\text { este cambio, si lo hay }\end{array}$ & $\begin{array}{l}\text { Sí. Se nota una diferencia positiva y significativa respecto a pocos años atrás. La Investigación en } \\
\text { la USMA ha sido desmitificada y es percibida ahora como algo interesante y, sobre todo, factible. } \\
\text { Y se nota en las estadísticas de los resultados de gestión. }\end{array}$ \\
\hline $\begin{array}{l}\text { Razones } \\
\text { responsables de ese } \\
\text { cambio o falta de } \\
\text { cambio }\end{array}$ & $\begin{array}{l}\text { Primero, un cambio de mentalidad en la alta gerencia. Segundo, que esto se ha traducido en una } \\
\text { asignación real de recursos financieros. Tercero, en la labor del equipo a cargo del área. Cuarto, en } \\
\text { la nueva mentalidad y mayor grado de compromiso de los profesores con estas tareas. Y Quinto, }\end{array}$ \\
\hline
\end{tabular}




\begin{tabular}{|l|l|}
\hline $\begin{array}{l}\text { Qué hay que hacer o } \\
\text { mejorar para } \\
\text { consolidar a la } \\
\begin{array}{l}\text { Investigación dentro } \\
\text { de la cultura } \\
\text { institucional }\end{array}\end{array}$ & $\begin{array}{l}\text { la fuerte presión que ha significado la evaluación y la acreditación y la labor de CONEAUPA, que } \\
\text { ha inducido estos cambios. } \\
\text { evaluación permanente como vía para detectar carencias y atenderlas. Extender programas a todos } \\
\text { los niveles, involucrando a todo el personal interesado. Crear incentivos de diverso tipo (escalafón, } \\
\text { remuneración, acceso a la capacitación, etc.). Divulgar más los beneficios de la actividad dentro } \\
\text { de nuestra comunidad, tanto para la institución como para sus miembros. }\end{array}$ \\
\hline $\begin{array}{l}\text { Observaciones } \\
\text { finales }\end{array}$ & $\begin{array}{l}\text { Principalmente el refuerzo en la preparación de tesis, la intervención para la mejora cualitativa de } \\
\text { los cursos de Metodología de la Investigación y el inicio de labores de investigación sobre procesos } \\
\text { institucionales, tanto administrativos como puramente docentes, que ayudarían muchísimo a la } \\
\text { reforma de la institución para su mejoramiento continuo. Extender este esfuerzo a toda la } \\
\text { Universidad, a nivel nacional. }\end{array}$ \\
\hline
\end{tabular}

Las Entrevistas a cuadros de alta gerencia demostraron que tiene plena conciencia de los factores determinantes de este cambio y de las medidas que hay que tomar para darles permanencia e impulso sostenido.

El análisis según Mayring sirvió para identificar categorías coincidentes derivadas de los resultados observados, identificándose ítems según su frecuencia de aparición, destacando tres factores como aquellos que muestran una alta frecuencia (reflejo de un alto grado de importancia para aquellos que fueron indagados): a) la preocupación por la asignación de recursos financieros para sostener las acciones investigativas; b) la necesidad de mantener acciones de apoyo técnico y seguimiento cercano; y c) la preocupación por hacer carrera académica que reconozca adecuadamente las tareas de investigación.

En la USMA ya se han comenzado a tomar algunos pasos de naturaleza orgánica, para darle sustancia y permanencia a estos cambios. Durante el segundo semestre de 2016, el Consejo Académico de la USMA aprobó un conjunto de documentos organizativos y normativos fundamentales para la continuidad de estos esfuerzos [14]. Con estas nuevas normativas, se fortalece la capacidad institucional de investigación y se plantea una estrategia para su sostenibilidad, basada en la institucionalización de políticas integrales y de acciones concretas para su desarrollo.

Como hemos visto, quedan aún como asignaturas pendientes la resolución de aspectos muy importantes tales como: la asignación permanente de un presupuesto suficiente, dedicado al desarrollo del área de I+D; el desarrollo e implantación de un sistema de estímulos (financieros y profesionales, dentro de un escalafón) para los académicos; acciones que perfeccionen la participación de los estudiantes avanzados en estas tareas (mejora en los cursos de Metodología de la Investigación, priorización de las tesis como opción para titularse). 
Invest. pens. crit. (ISSN 1812-3864)

Vol. 5, No. 1, enero-abril 2017

pp. $28-40$

\section{$5 \quad$ Referencias}

1. SIERRA PÉREZ, J.H. La investigación como prioridad universitaria. Revista Virtual, Universidad Católica Del Norte. Editada por la UCN, Colombia, 2014. v.12 fasc. 24.

2. WONG VEGA, L., CHENG, J., GÓlCHER, I. Análisis comparativo de la gestión de la Investigación Universitaria panameña. Investigación y Pensamiento Crítico. 2004 Vol. 2, No.1, pp. 40-50

3. RAMÍREZ, L. N. La educación universitaria pública y privada en la República Bolivariana de Venezuela. Mundo Universitario. 2010, No 35, pp. 04-09.

4. PARADA, J.R. Universidades públicas y privadas: un enfoque tridimensional. Estudios Públicos No. 120. CEP, Santiago de Chile, 2010.

5. IBARRA ARIAS, J.J.A., VILLAGRÁN GUERRERO, A.E. La investigación en las universidades privadas: ¿un lujo o una necesidad? Universidades, núm. 55, enero-marzo, pp. 48-55. Edit. Unión de Universidades de América Latina y el Caribe, México Distrito Federal, 2013.

6. UNIVERSIDAD CATÓLICA SANTA MARÍA LA ANTIGUA. Acreditación Institucional: Plan de Mejora 2012-2018. Panamá, 2012. 18 p.

7. SAN JUAN PABLO II. ExChorde Ecclesia. Constitución Apostólica del Sumo Pontífice Juan Pablo II sobre las universidades católicas. Libreria Editrice Vaticana, 1990.

8. UNIVERSIDAD CATÓLICA SANTA MARÍA LA ANTIGUA. Estatuto Orgánico. Panamá, 2008.

9. 87 p.

10. http://laestrella.com.pa/economia/usma-apuesta-proyectos-investigacion/23927583

11. WONG VEGA, L. Informe de Gestión del Director de Investigación correspondiente al año 2016.

12. KERLINGER, F.N., LEE, H.B. Investigación del comportamiento (4a ed.). México: McGraw-Hill, 2002.

13. TAYLOR, S.J., BOGDAN, R. Introducción a los métodos cualitativos en investigación. La búsqueda de los significados. Editorial Paidós, España, 1992, Págs.100 -132

14. MAYRING, P. Qualitative content analysis: theoretical foundation, basic procedures and software solution. Klagenfurt, Alemania, 2014.

15. UNIVERSIDAD CATÓLICA SANTA MARÍA LA ANTIGUA. Actas de las sesiones ordinarias del 26 de julio y del 27 de septiembre de 2016, del Consejo Académico de la USMA. 